\title{
Preferred genres and rhetorical modes in the humanities and social sciences
}

\author{
Adelia Carstens \\ Unit for Academic Literacy \\ University of Pretoria \\ adelia.carstens@up.ac.za
}

\begin{abstract}
The article reports on a research project aimed at identifying salient written genres and text types/rhetorical modes in the Faculty of Humanities at a large university in Gauteng, South Africa. The main purpose of the research was to establish an empirical base for the design of intermediate-level undergraduate language courses. A survey was done by means of text analysis: study guides were requested from a representative sample of departments, after which writing prompts were identified and analysed using Wordsmith Tools. In terms of genre it has been established that the humanities prefer essays and critical analyses, while the social sciences prefer project reports and essays. The rhetorical modes required most frequently at undergraduate level are discussion, analysis, argumentation, explanation and description. Discussion, explanation and argumentation are favoured by academic essays, while description and evaluation are favoured by reports, and analysis, argumentation and discussion are favoured by critical analyses. Although most essays presuppose argumentation, it is often not explicated in writing prompts. Other complicating factors are the ambiguity and hidden assumptions associated with certain rhetorical verbs. The outcomes of the research suggest two possible approaches to designing writing courses for undergraduate students in the humantities and social sciences: semi-generic approach, of which the latter may be more feasible within the framework of a macrouniversity.
\end{abstract}

Key words: academic essay, academic writing, genre, humanities, rhetorical mode, social sciences, text type

\section{Introduction}

This article reports on a research project aimed at gaining an impression of the written genres and rhetorical modes that are required by academic departments in a faculty of humanities at a large urban university, through examining a corpus of writing assignments included in study manuals. The ultimate goal is to use the results as input for designing intermediate-level undergraduate writing courses.

Since genre and rhetorical mode constitute the foci of the investigation, these concepts will be characterised briefly in the next section. The ensuing section provides an overview of previous empirical studies on genres and rhetorical modes in the university context. It is followed by a description of the research project that constitutes the focus of this article, and on the basis of the findings two possible routes for course design are identified.

\section{Genre and rhetorical mode}

Genres are the ways in which discourse communities, such as academic disciplines, achieve their purposes or goals (Swales 1990, 58 and 1998, 20; Paltridge 2002, 2; Hyland 2004, 44-47). Examples of genres are laboratory reports, case studies, essays, research reports, critical analyses, book reviews and project proposals. To teach academic writing effectively, course designers need to know which genres are preferred by the academic disciplines in question, and how these genres are structured in each disciplinary area.

Rhetorical modes or text types are groupings of texts that are similar in their internal linguistic form, irrespective of genre (Biber 1988, 170; Johns 2002, 6). The five modes mentioned across a broad spectrum of literature are narrative, exposition, explanation, argumentation and description. 
Some rhetorical studies, such as Tribble (1996), identify more than five rhetorical modes (also including exposition, exemplification, process, definition, cause and effect, comparison and contrast, division and classification, and persuasion), and others assume an intermediate position by maintaining the general modes, and subsuming a number of secondary modes under exposition, viz. process, classification/enmeration, exemplification (illustration), comparison and contrast, cause and effect, problem and solution, definition and analysis (Hale, Taylor, Bridgeman, Carson, Kroll \& Kantor 1996, 12-13). Course designers need to know which rhetorical modes are typically employed to support the purposes of particular disciplines and genre types.

\section{Previous studies on typologies of genre and rhetorical mode at tertiary institutions}

Coffin, Curry, Goodman, Hewings, Lillis and Swann $(2003,46)$ have made a broad categorisation of disciplinary areas and their preferred genres. According to them the natural sciences favour laboratory reports, and also write project proposals and reports, and also write project proposals and reports, fieldwork notes, essays and dissertations; the social sciences prefer essays and project reports, and also write fieldwork notes and dissertations; and the humanities emphasise essays, but also require critical analyses, translations and projects. Although this classification will resonate with the experience of most language lecturers, the authors do not give an explicit indication of its (empirical) basis. Other studies that claim to have examined genres and text types across the university empirically, for example Rose (1983); Horowitz (1986a and 1986b); Canseco and Byrd (1989); Carson, Chase, Gibson and Hargrove (1992); Braine (1995); Hale et al (1996); Moore and Morton (1998); and Melzer (2003) are not illuminating as a result of differences in their research designs: vastly different sampling techniques have been used, and different sets of categories are defined, some of which are a priori and others a posteriori. Moreover, none of these studies indicates if or how disciplinary purposes are linked to preferred genres and modes of discourse. If the contextualisation of linguistic input is to constitute a design principle of university-level writing courses (Kumaravadivelu 2006, $201 \mathrm{ff}$ ) this type of knowledge is indispensable to the applied linguist.

\section{The research project}

During the first quarter of 2007 ten university departments were approached to contribute copies of their study materials for analysis, viz. Music; Sociology; Historical and Heritage Studies; Visual Arts; Communication Pathology; Philosophy; Political Sciences; English; Social Work and Criminology; and Biokinetics, Sport and Leisure Sciences. The goal was to obtain a balanced representation of the humanities and social sciences. Toward that end, the following procedure was used.

First, an appointment was made with each head of department to explain the purpose and goals of the project, and to request copies of undergraduate study guides as well as other materials containing writing prompts. Some of the heads of department preferred to consult with their lecturing staff first. Two departments mentioned complicating factors, viz. the Department of Music and the Department of Communication Pathology. It was then mutually agreed to exclude these departments from the study. Written, informed consent was obtained from the heads of the other eight departments, as well as from each individual author who contributed materials. One of the limitations of the sampling method was self-selection: lecturing staff contributed study materials on a voluntary basis. This entailed that generalisation would be restricted.

The format/medium in which study materials were received, varied: Philosophy; Social Work and Criminology; Biokinetics, Sport and Leisure Sciences; Visual Arts; and Sociology provided hard copies of study guides, whereas English, Historical and Heritage Studies, and Political Sciences provided their documents in electronic format. When entering the data it was observed that the interpretation of certain writing prompts depended on guidelines for academic writing provided in 
general departmental manuals. These departments were requested to provide copies of such documents for contextualisation purposes. However, the manuals were not used to contribute data for the investigation.

Writing tasks were recorded by discipline. The procedure entailed search-reading the study materials, marking all writing prompts, and converting them to a computer-readable text format. The word-processing data were then transferred to a multicolumn matrix in Microsoft Word. This matrix contains slots for the code and name of each module, the full text of each writing prompt, the name of the genre as it occurs in the study guide - unless only a generic label such as 'assignment' or 'task' appears in the study guide, or the prompt has not been labelled - and a column for assigning a generic label that would form part of a formal classification scheme. Hale et al's (1996, 11-12) scheme, which was designed to assist in conceptualising the manner of assessing writing on the 2000 TOEFL test, was minimally adapted for this purpose. A possible weakness of this procedure is its reliance on a set of a priori genre categories combined with an interpretive categorisation procedure. However, the fact that many departments use only superordinate labels in their study guides rendered the use of in vivo categorisation unsuitable.

The first version of the classification scheme comprised seven genre categories: essay (the statement or development of a proposition or a point of view in a discursive format); summary (condensing information without discussion or elaboration); case study (analysis and presentation of a case situation); research report (a combination of prescribed forms of writing, such as a statement of objectives, description of a method, and presentation of results); plan/proposal (the approach used for addressing an issue or solving a problem); book review (summary of the content and analysis/evaluation of the points made); unstructured writing (putting thoughts on paper without structural constraints, or where the writer records thoughts and events as freestanding observations, such as journal entries).

During the process of analysing and categorising data, the following adjustments were made to the schema:

- Instead of adding a category to accommodate the literature review, it was subsumed under the category essay, as most essays require the consultation of external sources.

- For the genre critical analysis a separate (eighth) category was created because the discourse structure of this genre is largely standardised. A critical analysis typically involves a summary of the content, relating some aspect of that content to the topic, providing a thesis statement, and developing the argument by providing details from the artefact being analysed.

- The category research report was found to be too specific to subsume the large variety of report types required, and therefore the superordinate report was used.

- Following Hale et al $(1996,11)$, assignments in which the writer is asked to analyse an already written case study were subclassified as a case study analysis in the essay genre.

- To accommodate multimodal genres involving a substantial amount of written text, a ninth category was added, viz. the audiovisual presentation.

- For the sake of completeness portfolio was added.

Based on the assumption that the instructional verbs used in writing prompts provided students with cues about the modes of writing that are required, a systematic analysis of all writing prompts was conducted, using Wordsmith Tools version 4.0. A point of criticism that might be raised against this procedure is that the boundary between rhetorical mode and cognitive demand, as instantiated by Bloom's taxonomy of educational objectives, becomes blurred. Although such reservations might be warranted, one could also argue that instructional verbs have a dual function: they give an indication of whether the required action is at a higher or lower level, and of the rhetorical organization of the content. Describe, for instance, represents a lowerlevel cognitive demand, and also indicates to the student that a recording has to be given of sense impressions and qualities of a type, class or group (compare Hale et al 1996, 12-13). 
First, a list of search terms for building concordances was compiled from scholarly sources, including Weissberg and Buker (1990, 184-192), Cope and Kalantzis (1993, 9-10), Hale et al (1996, 12-15); Macken-Horarik (2002, 21-22 and 37-38), Paltridge (2002, 81-82), and Hyland $(2006,48)$. The eventual list contained search terms (mostly wildcards) for the following rhetorical modes: analysis, argumentation (give your opinion), cause and effect, classification, comparison and contrast, definition, description, discussion, exemplification, exposition, evaluation, illustration, narration, procedure, process, recount, reflection and summary (make a synopsis). Figure 1 below is a screen capture showing the first 21 lines of the concordance for the search term expla* (representing explain, explanation and explanatory):

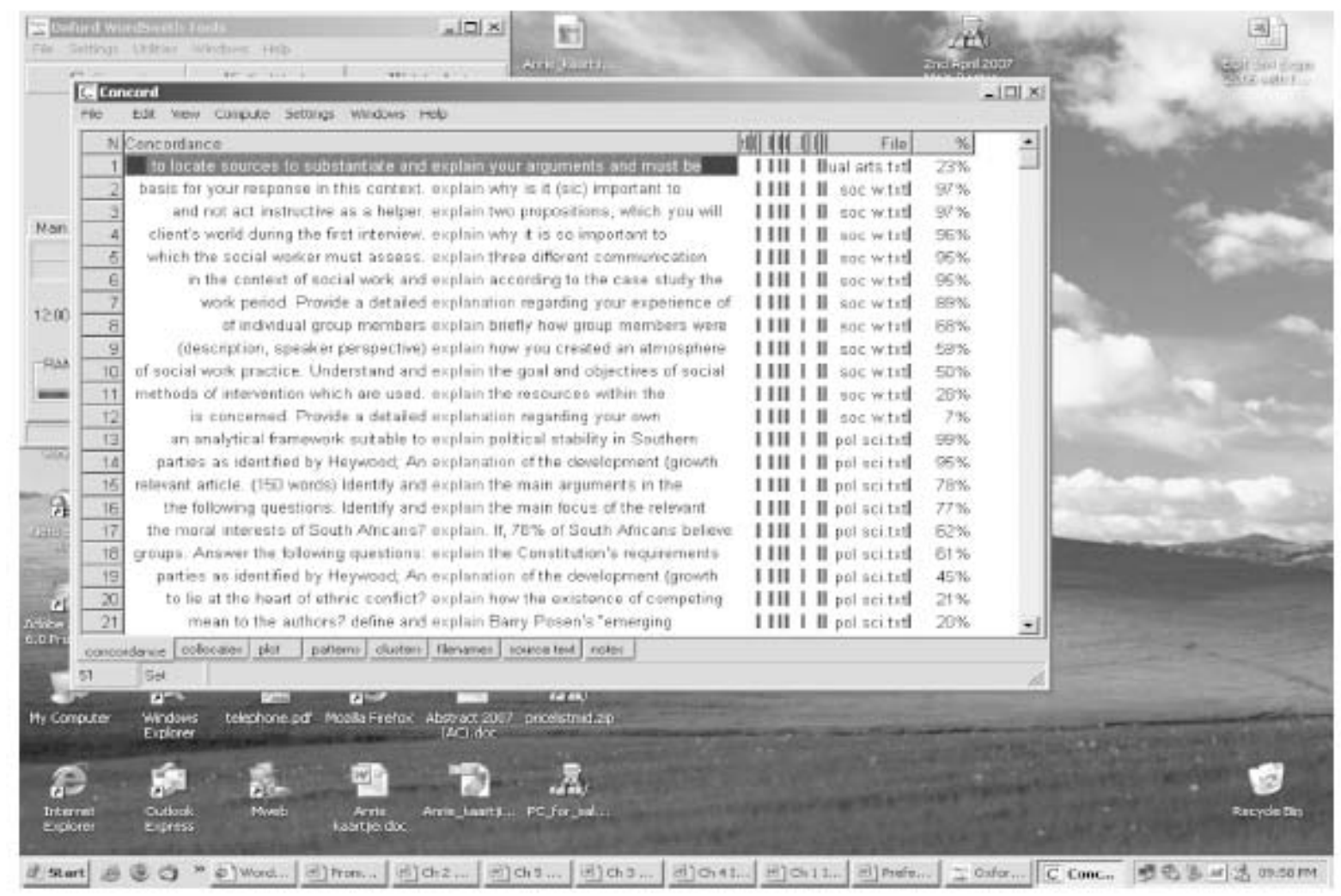

\section{Figure 1: Screen capture of the concordance for expla}

After recording the findings by department, a summary was sent to each head of department, with an invitation to comment if it was felt that the discipline was misrepresented. Three departments responded: English, Historical and Heritage Studies, and Studies questioned the researcher's interpretation of their use of the verb discuss. The criticism was regarded as valid and constructive, and the final report (see discussion) was adjusted accordingly.

\section{Discussion of findings}

Already at the data recording stage meaningful variation across disciplines became apparent, particularly in terms of reference to rhetorical modes, and preferences with regard to genre and rhetorical mode. In this section a partially quantitative and partially interpretive overview of the findings will be given according to discipline, followed by tabulated summaries of the data.

\section{Department of Biokinetics, Sport and Leisure Sciences}

The Department of Biokinetics, Sport and Leisure Sciences contributed 21 study guides. 
Since sport studies is largely an applied science it was anticipated that assignments would be less 'essayist' than other disciplines in the humanities and social sciences, and more oriented towards application, teamwork and organisation. This was, in fact, borne out of the findings: 17 of the 22 assignments in the subcorpus are group assignments, six of which are written essays with a strong emphasis on the application of theory. Eleven assignments belong to a genre that does not occur in any of the other subcorpora, viz. the expo assignment, which is typically an oral group presentation, supported by a poster, a model or an electronic slide show. The expo assignment was assigned to the category audiovisual presentation in the formal classification scheme.

Only one individual written assignment (essay) and one individual oral presentation occur in the subcorpus. The remaining genres comprise three portfolios (containing written work of restricted scope) and a business plan. The latter is required for a module on sports management.

In the Biokinetics subcorpus illustrate, with its variants illustration and illustrated, is the only rhetorical mode to occur relatively frequently, mostly in prompts for expo assignments (15 times out of 25 occurrences in the combined corpus). If one considers that in seven instances (in the combined corpus) illustration and illustrated refer to visual material instead of speech acts, the number of occurrences of illustrate in the Biokinetics corpus is 15 out of a total of 18. Of the remaining three, one occurs in the Visual Arts corpus, one in the Historical and Heritage Studies corpus and one in the Social Work corpus.

Reflect and its past tense form occur six times out of a total of 15. However, it is not used to refer to a mode of writing, and is therefore not relevant for consideration in this used to refer to a mode of writing, and is therefore not relevant for consideration in this regard. Compare, for instance: 'Expo material must reflect scientific research methods (x2)', '[...] reflect a specific theme', and '[...] reflect an understanding.

\section{Department of English}

The seven study guides volunteered by the Department of English contributed 31 assignments to the corpus: 14 critical analyses and 17 essays, of which six require a primarily argumentative mode of exposition, three require compare and contrast as their principal structuring mechanism, two call for the description of a process, and one is overtly descriptive. Five of the essays are described as 'more challenging', including two comparisons, one description and two explanations. The rhetorical modes that feature most prominently in the English corpus are argumentation and (critical) analysis and 17 essays, of which six require a primarily argumentative mode of exposition, three require compare and contrast as their principal structuring mechanism, two call for the description of a process, and one is overtly descriptive. Five of the essays are described as 'more challenging', including two comparisons, one description and two explanations.

The rhetorical modes that feature most prominently in the English corpus are argumentation and (critical) analysis. This finding is not surprising, as much of the academic activity in English literature courses is focused on evaluating literary artefacts by analysing them and giving reasons for interpretations. The collocation critical analysis occurs no fewer than 12 times in the subcorpus. A critical argumentative mode is further signalled by the prolific use of the word comment (both the noun and the verb). The English corpus accounts for 27 instances out of a total of 33. Furthermore, discuss and its morphological variants occur 20 times out of 107.

\section{Department of Visual Arts}

The Department of Visual Arts contributed 11 study guides containing ten writing prompts: five essays, four critical analyses (of works of art, exhibitions and artefacts), and one research report. Four of the five essays are critical reflections on the artist's work, required in practical modules such as Information Design. The importance of self-reflection is underscored by the use of cognition verbs such as reflect, contemplate, consider and understand. 
The relative prominence of the rhetorical mode analysis in theoretical modules, viz. History of Art, is predictable in the light of the salience of the critical analysis genre: eight out of 61 is quite significant, given the moderate amount of data provided by the Visual Arts Department. In most instances the instructional phase critically discuss is used (seven times out of a total of 35 occurrences of this collocation in the combined database), and usually involves selecting one or more representative examples, critiquing these, and supporting evaluative statements with evidence from an exhibition/work of art, theory, research, etc. Another rhetorical mode with a fairly strong representation is argumentation. The noun argument and its morphological variants occur eight times out of a total of 31 . This finding is not surprising, as arguments usually need to be put forward in support of analysis and evaluation.

\section{Department of Historical and Heritage Studies}

The Department of Historical and Heritage Studies houses three subdisciplines, viz. History, Cultural History, and Heritage and Cultural Tourism. Twenty-one study guides were received in an electronic format, comprising 76 writing prompts, the majority of which require essays (62): long (25), short (23), comparative (1), descriptive (2), explanatory (5), argumentative (6). Other assignments include two book reviews, two critical analyses, one itinerary, one oral presentation, two portfolios, and six reports on museum visits. The subdiscipline of History is dominated by essays, whereas Cultural History, and Heritage and Cultural Tourism make use of a larger variety of genres including essays, reports on museum visits, book reviews, an itinerary, portfolios and an oral presentation. The variation in these subdisciplines is comparable to practice-oriented disciplines such as Social Work; and Biokinetics, Sport and Leisure Sciences.

According to sources on writing about history, such as Marius and Page $(2005,52-74)$, historical writing is characterised by four main rhetorical modes, viz. narration, description, argumentation and exposition (for which analysis is often used as a synonym). In the field of history exposition and analysis invariably require explanation, which in turn requires identifying possible causes for particular effects.

All four modes were found to enjoy prominence in the Historical and Heritage Studies subcorpus, albeit not explicitly. Analysis/exposition is represented by the verb explain, which occurs 25 times out of a total of 51 . The high frequency of the verb explain in the History corpus is in line with one of the core objectives of this subject field, viz. 'to make sense of a historical event by providing reasons for it having occurred' (Department of Historical and Heritage Studies 2006, 8). Describe occurs 13 times out of a total of 51, and fulfils more than one rhetorical function: it denotes both narration ('relating a series of events in a chronological order') and description, in the sense of 'recording a particular sensory experience'. Initially argumentation seemed to be underrepresented in the subcorpus, given the emphasis it receives in the departmental study manual. However, after close scrutiny of the various concordances it became apparent that discuss, which occurs 25 times out of a total of 107, invariably implies argumentation. Compare the definition given for discuss in the Study Manual (Department of Historical and Heritage Studies 2006, 8): 'to examine critically through argument.' Supporting evidence for the importance of argumentation in the field of Historical and Heritage Studies is also found in the prominence of the noun opinion, which occurs five times out of a total of ten in the combined corpus.

\section{Department of Philosophy}

The five study guides that were provided contain eight essay assignments. Four of these are overtly argumentative, as suggested by expressions such as argue, discuss, take a definite stand on, and develop your own point of view, and four belong to other essay types. One assignment, a service module offered to Commerce students, is a journal.

Argumentation is clearly the most salient rhetorical mode, despite the relatively few occurrences of its lexical instantiations in the subcorpus: four out of 31 . The relatively low frequency in the essay prompts may be partially due to the size of the subcorpus, and owing to the elaborate 
explanation of this mode in general departmental literature. Compare, for instance, the following description of the mode in the organisational component of the introductory first-year module:

Start with the assumption that your reader knows nothing about the subject that you are writing about, or if your reader knows something about the subject, that $\mathrm{s} / \mathrm{he}$ does not share your point of view. Your readers will only share your view if you could convince them. Consequently you have to provide convincing reasons in support of your point of view.

\section{Department of Political Sciences}

Twelve study guides, which include 14 writing prompts, were received electronically. Eight of these are essays, ranging from 1400 to 3000 words per essay. Longer essays have to be accompanied by a synopsis. The rest of the corpus consists of a research report, two comprehension tests requiring relatively short answers, two more difficult comprehension exercises, and a critical group discussion of a scientific article, followed by a report by the group leader. The comprehension tests and the critical group discussion were categorised as critical analyses.

The rhetorical modes featuring prominently in this subcorpus are discuss, argue, summarise and explain. Argumentation assumes a central position: the verb argue and other morphological variants occur 12 times out of a total of 31 instances; and the word discuss and its variants occur 29 times out of a total of 107. An interesting finding was the prominence of the prominence of summarising: the word summarise occurs three times out of a total of ten, and the word synopsis occurs ten times, which represents the total number of occurrences in the entire corpus. Possible reasons for the emphasis on summarizing are improving reading skills, assessing comprehension and facilitating preparation for professional activities that require condensing a bulk of literature. Similar to Historical and Heritage Studies, Political Sciences focused strongly on issues of cause and effect, albeit being focused more on the present and the future than on the past. It is thus not surprising that the word explain and other morphological variants comprise a fifth of the total of 51 occurrences.

\section{Department of Social Work and Criminology}

The Department of social work and Criminology contributed ten study guides, of which only two came from the Criminology subdepartment. It was decided not to include the criminology materials, since the data would not be sufficient to allow generalisation.

The social work materials include 20 assignments, dominated by reports on social interventions with individuals, groups and communities. Included are a report on voluntary work, a report on social work intervention with individuals (based on a situation analysis), a report on observation at an NGO, a report on social work intervention with individuals (interview), and a report on projects addressing specialized fields. One research report was required. In three cases the report comprises a genre set, i.e. it is made up of two or more genres that contribute towards a common purpose. Two genres are associated with the activity 'intervention with communities', viz. a preparatory report and a final report. Another genre set, which is associated with 'intervention with groups' comprises a group work proposal, a report on the course of a session (also called a process report), and a comprehensive group work report. For each type of report a template prescribing the discourse structure is provided in the study guide: Social Work Practice. In the theoretical component of Social Work the following genres are required: an analysis of a scientific article, two literature reviews, a research report, one individual and one group essay on professional values and processes (and their practical applications), a critical analysis of a case study, and a critical evaluation of a previous assignment.

The three text types/rhetorical modes with the strongest representation in the Social Work subcorpus are evaluation (31 out of a total of 51), description (28 out of a total of 51, analysis (11 out of a total of 61), and discussion (22 out of a total of 107). The high frequencies of evaluation and description can be explained with reference to the main purpose and the discourse structure 
of reports in this subject field: reports mainly comprise a descriptive and an evaluative component. Processes, actions, events, outcomes and institutions are typically described after close observation (compare phrases such as ' the target group', ' the organisation', ' $\sim$ the experience you gained', ' $\sim$ the knowledge you gained', ' $\sim$ your impression of [...]', ' $\sim$ the roles you played', ' the value of [...]', and ' your own perception'), and then evaluated or reflected upon. An analysis of the concordance materials revealed that discuss and discussion are used as synonyms of describe and description in 50\% of instances (11 out of 22 in the concordance of 107 occurrences). In the other half of the cases discuss primarily requires the student to consider a problem or an issue from more than one point of view (the primary rhetorical meaning of the term discuss). In a few instances a recount, procedure or narrative is required, as in 'discuss the course of the intervention', 'provide a discussion of how you plan to assess', 'discuss the aim and objectives', and 'discuss your introduction to the client'.

\section{Department of Sociology}

Three essay prompts occur in the four study guides received from the Department of Sociology, two of which are research reports, and the third is an argumentative essay. All essay prompts are underpinned by a comprehensive set of guidelines provided in the departmental guide.

The pivotal rhetorical mode seems to be argumentation. The verb argue and the nominal forms argument and argumentation occur seven times in the subcorpus - almost a quarter of the total number of occurrences in the corpus.

\section{Summary and interpretation of data}

The quantitative findings concerning genres and text types are summarized in Table 1:

Table 1: Summary of salient genres and text types/rhetorical modes in the humanities and social sciences

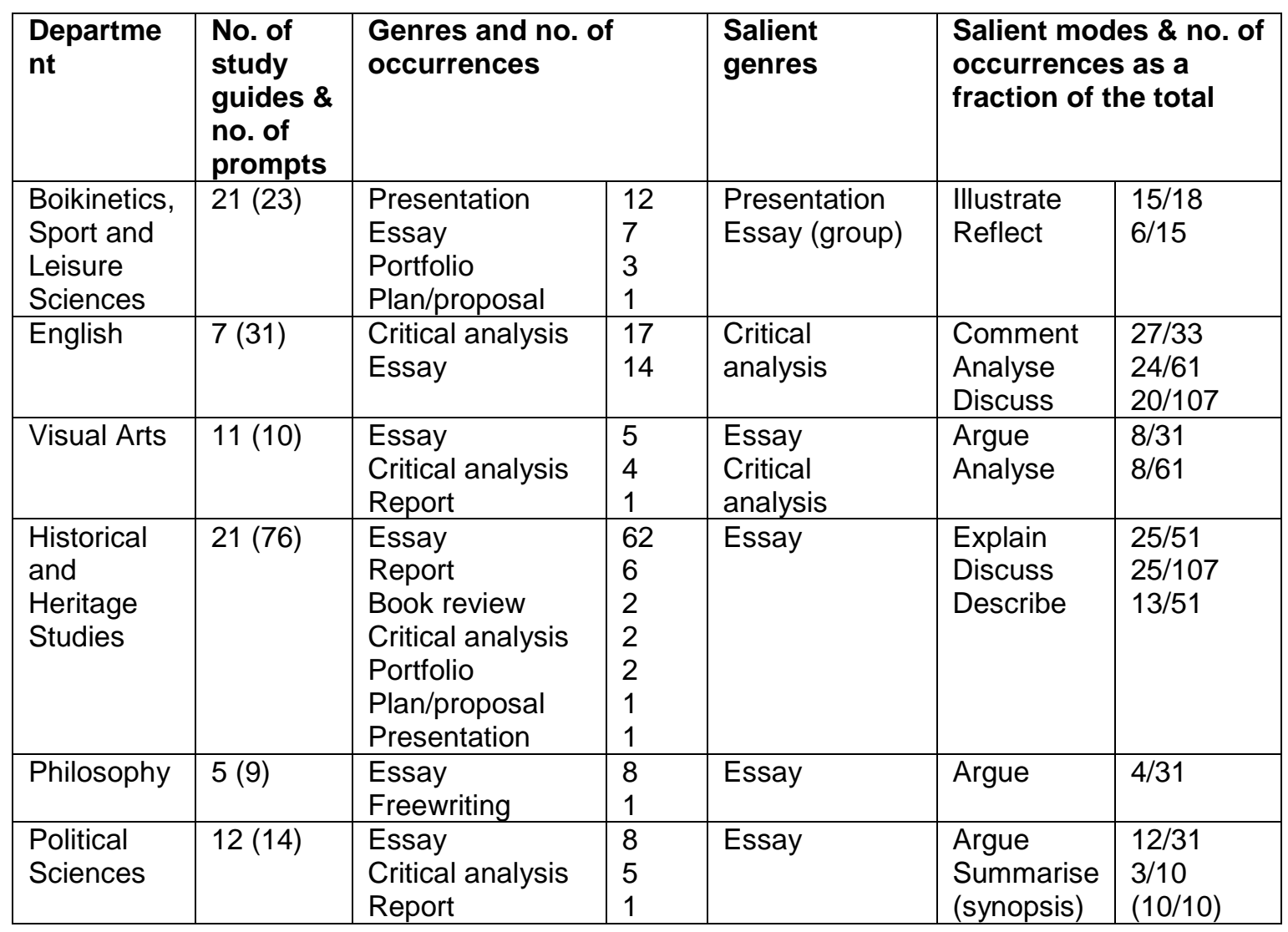




\begin{tabular}{|l|l|l|l|l|l|l|}
\hline & & & & & $\begin{array}{l}\text { Discuss } \\
\text { Explain }\end{array}$ & $\begin{array}{l}29 / 107 \\
10 / 51\end{array}$ \\
\hline Social & $8(20)$ & Report & 9 & Report & Evaluate & $31 / 51$ \\
Work & & Plan/proposal & 2 & Essay & Describe & $28 / 51$ \\
& & Critical analysis & 2 & & & Analyse \\
Discuss & $11 / 61$ \\
& & Essay & 5 & & & $22 / 107$ \\
& & Presentation & 2 & & & \\
\hline Sociology & $4(3)$ & Report & 2 & Report & Argue & $7 / 31$ \\
& & Essay & 1 & & & \\
\hline
\end{tabular}

To the extent that these figures are representative, the findings regarding genres largely coincide with the categorisation of Coffin et al (2003), viz. that the humanities have a preference for essays and critical analyses, and the social sciences prefer project reports and essays. Table 2 gives a breakdown of the preferred assignment genres per academic department:

Table 2: Ratio of salient assignment genres to total no. of assignments per department

\begin{tabular}{|l|l|l|l|l|}
\hline Department & \multicolumn{2}{|l|}{ No. of assignments in salient categories and ratio } & $\begin{array}{l}\text { Total no. of } \\
\text { assignments } \\
\text { per dept. }\end{array}$ \\
\hline & Essay & Reports & Critical analysis & \\
\hline $\begin{array}{l}\text { Biokinetics, Sport } \\
\text { and Leisure } \\
\text { Sciences }\end{array}$ & $7(30 \%)$ & $0(0 \%)$ & $0(0 \%)$ & 23 \\
\hline English & $14(45 \%)$ & $0(0 \%)$ & $17(55 \%)$ & 31 \\
\hline Visual Arts & $5(50 \%)$ & $1(10 \%)$ & $4(40 \%)$ & 10 \\
\hline $\begin{array}{l}\text { Historical and } \\
\text { Heritage Studies }\end{array}$ & $62(82 \%)$ & $6(8 \%)$ & $2(3 \%)$ & 76 \\
\hline & & & & \\
\hline & & & & \\
\hline & & & & 14 \\
\hline & $8(89 \%)$ & $0(0 \%)$ & $0(0 \%)$ & 20 \\
\hline $\begin{array}{l}\text { Philosophy } \\
\text { Sciitical }\end{array}$ & $8(57 \%)$ & $1(7 \%)$ & $5(36 \%)$ & 3 \\
\hline Social Work & $5(20 \%)$ & $9(45 \%)$ & $0(0 \%)$ & \\
\hline Sociology & $1(33 \%)$ & $2(66 \%)$ & $0(0 \%)$ & \\
\hline
\end{tabular}

These figures may be used as a rationale for concentrating on the academic essay in writing courses aimed at students in the humanities and research-oriented social sciences. For students in service-oriented social science departments, such as Social Work, a course on report writing may be useful.

As far as rhetorical modes are concerned, the data indicate that discussion is the most prolific (107 occurrences in the combined database), followed by analysis (61 occurrences), description (51 occurrences), explanation (51 occurrences) and argument + (give your) opinion (41 occurrences). Although these figures shed some light on the salience of rhetorical modes in the humanities and social sciences, they still do not tell us whether certain genres favour specific modes. To explore possible affinities separate databases were built for each of the terms denoting the most salient genres, viz. essay, report and critical analysis. Table 3 summarises the findings with regard to the modes highlighted above.

Table 3: Relationships between salient genres and preferred rhetorical modes 


\begin{tabular}{|l|l|c|}
\hline $\begin{array}{l}\text { Genre } \\
\text { (Word count per genre } \\
\text { category in brackets) }\end{array}$ & Rhetorical mode & $\begin{array}{l}\text { No. of occurrences of the } \\
\text { mode in the genre subcopus }\end{array}$ \\
\hline \multirow{5}{*}{ Essay (4201 words) } & discuss & 48 \\
\cline { 2 - 3 } & explain & 27 \\
\cline { 2 - 3 } & argue (+ give your opinion) & $12(+8)=20$ \\
\cline { 2 - 3 } & describe & 13 \\
\cline { 2 - 3 } & analyse & 0 \\
\cline { 2 - 3 } & evaluate & 27 \\
\hline \multirow{5}{*}{ Report (2219 words) } & evaluate & 23 \\
\cline { 2 - 3 } & describe & 18 \\
\cline { 2 - 3 } & discuss & 3 \\
\cline { 2 - 3 } & explain & 0 \\
\cline { 2 - 3 } & analyse & 0 \\
\cline { 2 - 3 } & argue & 16 \\
\hline Critical analysis (489 words) & analyse & 8 \\
\hline & argue & 4 \\
\hline & discuss & 0 \\
\hline & describe & 0 \\
\hline & explain & 0 \\
\hline & evaluate & 0 \\
\hline
\end{tabular}

According to the table discussion, explanation and argumentation are the rhetorical modes favoured by essays; evaluation, description and discussion by reports; and analysis, argumentation and discussion by critical analyses.

Given the fact that verbs such as analyse, discuss and explain usually presuppose argumentation, and given the emphasis on the skill of arguing a case in departmental manuals, it is a far more important mode than is reflected by the concordances. In general, the findings should be interpreted with circumspection. Because of the ambiguity of certain lexical items: discuss, for instance, is used in three distinct senses: (1) 'to consider a problem or an issue from more than one point of view in the light of some kind of frame or position'; (2) 'to provide a detailed account of a particular sensory experience', and (3) 'to provide an account of an event in the order that things happened or should happen'. In other words it is also used to denote description, narrative, recount and process. With regard to the report genre, the term is mostly used in sense (1), and occasionally in sense (3), whereas the essay genre mostly activates sense (2).'to provide a detailed account of a particular sensory experience', and (3) 'to provide an account of an event in the order that things happened of should happen'. In other words it is also used to denote description, narrative, recount and process. With regard to the report genre, the term is mostly used in sense (1), and occasionally in sense (3), whereas the essay genre mostly activates sense (2). Conventions of the subject-field also play a role in this regard: in Social Work corpus sense (1) dominates, whereas sense (2) dominates in Historical and Heritage Studies, and Political Sciences. Describe is also ambiguous in terms of senses (2) and (3) above, which it shares with discuss.

In other words, although certain generalisations can be made on the basis of frequency counts it is important, in addition, to analyse data qualitatively in order to take note of the idiosyncratic conventions of different discourse communities.

\section{The way forward}

The outcomes of this study suggest two possible strategies for improving the writing abilities of students in the humanities and social sciences: one is focused on academic genres appropriate for a specific course and level as part of course content, and the other is focused on a number of typical genres, using models/examples from different disciplines. Drury $(2006,235)$ uses the 
terms 'field-rich' and 'context-rich' for these two possibilities, which are generally referred to as 'discipline-specific' and 'generic'.

Field-rich courses require a close fit between the purposes and conventions of disciplinary communities on the one hand, and the writing conventions that are taught. Such courses should ideally be mapped on the syllabus of the subject-field in question, and close collaboration between writing teachers and academic lecturers is desirable. Although the majority of students and academic lecturers would cast their votes for field-rich courses, this option may not be feasible at a large urban university with a sparsely staffed writing unit.

The remaining option would be semi-generic courses for students of disciplinary clusters, such as the humanities and social sciences. The research conducted for this article indicated that variation is limited within this cluster, and the findings could be used in support of more generic courses on essay-writing and report-writing. However, designing a semi-generic course on, for example, essay-writing, is easier said than done. Despite efforts to define the discourse structure of the academic essay (compare for instance Hyland 1990), numerous researchers have highlighted its amorphous nature and the difficulties associated with teaching this genre (compare Hounsell 1987; Dudley-Evans 2002; Lillis 2001). Dudley-Evans (2002, 228), for instance, regards the different sections or moves of an essay as mere 'strands of discourse' that 'recur discontinuously throughout a particular language event and, taken together, structure that event'. Variation across disciplines only compounds the problem. Dudley-Evans (ibid) then expresses his preference for teaching the general characteristics of academic writing, such as the language of objectivity, instead of the genre structure and lexicogrammatical features associated with particular genres.

On the other hand it could be argued that variability, lexical ambiguity and hidden rhetorical assumptions (compare Hounsell 1987; Dudley-Evans 2002; and Lillis 2001) do not render a particular genre 'unteachable'. In fact, the majority of academic disciplines in the Faculty of Humanities at the institution where the research was conducted prescribe a basic tripartite structural template, comprising an introduction (containing at least a thesis statement), a body, and a conclusion in their departmental manuals. Almost without exception they emphasise the importance of argumentation. What is often lacking is a systematic explanation of how the discourse structure of the essay and the relevant modes of writing support the purposes of the writer and the discourse community. Focusing on functional variation within and between disciplines may benefit students in that they will be enable to develop an awareness of what is valued by different discourse communities, and how discursive purposes and linguistic choices vary systematically (Lillis 2001, 56-57; Hewings \& Hewings 2006, 200).

\section{Conclusion}

The research project on which this article reports showed that the academic essay is the written genre most frequently required by lecturers in the humanities and researchoriented social sciences at the tertiary institution under scrutiny. Practice-oriented social sciences, such as Social Work, seem to favour informative reports.

It has also been established that students are expected to master various modes of writing. In essay-writing argumentation (for which the synonym exposition is often used in scholarly literature on writing) is a critically important mode. However, it is lexicalised in various ways. Instructional verbs such as argue, discuss, debate, explain, analyse and evaluate (and their nominalised forms) signal this mode, although slightly different configurations may be required. Less complex modes, such as description, cause and effect, comparison and contrast, exemplification and definition, are invoked to support the argumentative stance.

With a view to course design it may be concluded that both semi-generic and subject-specific courses on essay-writing and/or report writing for students of the humanities and social sciences are merited. Subject-specific courses will probably be preferred by students, and such courses 
may be more effective because of the more direct mapping between the content of the writing course on the one hand, and disciplinary purposes and learning outcomes on the other.

Although a focus on genres and rhetorical modes may remind one of outdated language teaching methods, such as the current-traditional approach, the course designer does not need to revert back to transmission pedagogy. Genre and rhetorical mode may be used as focal points from a content point of view, while the pedagogical approach may be one of principled pragmatism (compare Kumaravadivelu 2003 and 2006; Weideman 2003). Such an approach should ideally build on the learner's prior academic experience and needs, and target situation requirements while concentrating more on cognitive processes than on the final product.

\section{References}

Bhatia, V. K. 2002. A generic view of academic discourse. In Academic discourse, ed. J. Flowerdew, 21-39. London: Pearson Education.

Biber, D. 1988. Variation across speech and language. Oxford: Oxford University

Press.

Braine, G. 1995. Writing in the natural sciences and engineering. In Academic writing in a second language. Essays on research and pedagogy, ed. D. Belcher and G. Braine, 113-134. Norwood, NJ: Ablex.

Canseco, G. and P. Byrd. 1989. Writing requirements in graduate courses in business administration. TESOL Quarterly 23: 305-316.

Coffin, C., M. Curry, S. Goodman, A. Hewings, T. Lills and J. Swann. 2003. Teaching academic writing: A toolkit for higher education. London: Routledge.

Cope, B. and M. Kalantzis, eds. 1993. Powers of literacy: A genre approach to teaching writing. London: Falmer Press.

Department of Historical and Heritage Studies. 2006. Study manual. University of

Pretoria.

Drury, H. 2006. Short answers in first-year undergraduate science writing. What kind of genres are they? In Academic writing in context, ed. M. Hewings, 104-121. London:

Continuum.

Dudley-Evans, T. 2002. The teaching of the academic essay: Is a genre approach possible? In Genre in the classroom: Multiple perspectives, ed. A. M. Johns, 225-235.

London: Lawrence Erlbaum.

Hale, G., C. Taylor, B. Bridgeman, J. Carson, B. Kroll and R. Kantor. 1996. A study of writing tasks assigned in academic degree programs. TOEFL. Research Report No.

54. Princeton, NJ: Educational Testing Service.

Hewings, A. and M. Hewings. 2006. Anticipatory 'it' in academic writing: An indicator of disciplinary difference and developing disciplinary knowledge. In Academic writing in context, ed. M. Hewings, 199-214. London: Continuum.

Horowitz, D. 1986a. Essay examination prompts and the teaching of academic writing.

English for Specific Purposes 5: 107-120. .1986b. What professors actually require: Academic tasks for the ESL classroom. TESOL Quarterly 20: 445-482.

Hounsell, D. 1987. Essay writing and the quality of feedback. In Student learning:

Research in education and cognitive psychology, ed. J. T. E. Richardson, M. W.

Eysinck and D. W. Piper. Milton Keynes: Open University Press.

Hyland, K. 1994. Hedging in academic textbooks and EAP. English for Specific Purposes 3(3): 239-256.

Press. 2004. Genre and second language writing. Ann Arbor: University of Michigan 2006. English for academic purposes. London: Routledge.

Johns, A. M. 2002. Introduction. In Genre in the classroom. Multiple perspectives, ed. A. M. Johns, 3-13. London: Lawrence Erlbaum.

Kumaravadivelu, B. 2003. Beyond methods: Macrostrategies for language teaching. New Haven, CT: Yale University Press. . 2006. Understanding language teaching: From method to postmethod. Mahwah, New Jersey: Lawrence Erlbaum Associates. 
Lillis, T. 2001. Student writing: Access, regulation and desire. London: Routledge Macken-Horarik, M. 2002. 'Something to shoot for': A systemic functional approach to teaching genre in secondary school science. In Genre in the classroom: Multiple perspectives, ed. A. M. Johns, 43-72. London: Lawrence Erlbaum.

Marius, R. and M. E. Page, 2005. A Short guide to writing about history (5thedition). New York: Pearson Education.

Melzer, D. 2003. Assignments across the curriculum. A survey of college writing. Language across the disciplines. http://wac.colostate.edu (accessed 6 February 2007).

Moore, T. and J. Morton. 1998. Contrasting rhetorics: Academic writing and the IELTS test. Paper presented at the Australian Council of TESOL Associations, Victorian Association for TESOL and Multicultural Education National Conference, Melbourne.

Paltridge, B. 1996. Genre, text type and the language learning classroom. ELT Journal

50(3): 237-243.

2001. Genre and the language learning classroom. Ann Arbor: University of Michigan Press.

2002. Genre, text type, and the English for Academic Purposes (EAP) classroom.

In Genre in the classroom: Multiple perspectives, ed. A. M. Johns, 73-90. London:

Lawrence Erlbaum.

Rose, M. 1983. Remedial writing courses: A critique and a proposal. College English

45: 109-126.

Swales, J. 1990. Genre analysis: English in academic and research settings. Cambridge:

Cambridge University Press.

Tribble, C. 1996. Writing. Oxford: Oxford University Press.

Weideman, A. 2003. Justifying course and task design in language teaching. Acta

Academica 35(3): 26-48.

Weissberg, R. and S. Buker. 1990. Writing up research. Englewood Cliffs, NJ: Prentice

Hall. 